\title{
Molecular characterisation of rough variants of Vibrio cholerae isolated from hospitalised patients with diarrhoea
}

\author{
RUPAK. K. MITRA* $\S$, RANJAN K. NANDY*, THANDAVARAYAN RAMAMURTHY*, \\ SUJIT K. BHATTACHARYA*, SHINJI YAMASAKI†, TOSHIO SHIMADA $\$$, YOSHIFUMI TAKEDA \\ and G. BALAKRISH NAIR*
}

* National Institute of Cholera and Enteric Diseases, Beliaghata, Calcutta 700 010, India; †Research Institute, International Medical Center of Japan, Shinjuku, Tokyo 162-8655, Japan and \$National Institute of Infectious Diseases, Shinjuku, Tokyo 162-8640, Japan

\begin{abstract}
Seven rough isolates of Vibrio cholerae isolated as the sole infecting agent from patients with cholera-like diarrhoea were examined for the presence of the regulatory element tox $R$ and certain virulence-associated genes of the CTX genetic element and $V$. cholerae pathogenicity island (VPI). Multiplex PCR analysis with $w b$-specific genes of either 01 or 0139 origin showed that six of the seven isolates produced an $01 w b$-specific amplicon and the remaining isolate produced an O139-specific amplicon. Analysis of lipopolysaccharide profiles of smooth variants of $\boldsymbol{V}$. cholerae revealed the presence of long repeated units of ' $O$ ' polysaccharide side chains but all the rough variants appeared to be devoid of the latter and possessed only core oligosaccharide. PCR amplification with primers specific to the $\operatorname{ctx} A, \operatorname{ctx} B, \operatorname{tcp} A, \operatorname{tag} A$, int, ald $A, \operatorname{tox} T, L J, R J$ and $\operatorname{tox} R$ genes revealed that six of the seven rough isolates were positive for these genes. One isolate was found to be negative for $\operatorname{tag} A$ and $R J$, indicating the presence of an altered VPI. Each of these isolates showed mediadependent expression of cholera toxin (CT) and produced more toxin than the reference $V$. cholerae 01 EI Tor strain VC20 or 0139 strain SG24 under comparable conditions. Studies on the clonality of these isolates by the analysis of rRNA genes indicated their relatedness to strains of $V$. cholerae $\mathrm{O} 1 \mathrm{El}$ Tor or $\mathrm{O139}$, isolated during the same time period.
\end{abstract}

\section{Introduction}

Vibrio cholerae, the aetiological agent of cholera, is classfied on the basis of the heat-stable somatic ' $O$ ' antigen into more than 193 serogroups [1]. The antigenic specificity of the repetitive units of the polysaccharides (' $\mathrm{O}$ ' antigen) of the lipopolysaccharide (LPS) forms the basis of the $V$. cholerae serotyping scheme [2]. The use of flagellar $(\mathrm{H})$ antigen has no practical applicability in this scheme, as all strains of a given Vibrio species share an identical H antigen [3]. Traditionally, strains belonging to serotype $\mathrm{O} 1$ were responsible for epidemics and pandemics of cholera [4,5]. In late 1992, $V$. cholerae strains which did not agglutinate with the ' $\mathrm{O}$ ' specific antisera then available emerged as the causative agent of epidemic cholera and were later designated as 0139 Bengal [6]. V. cholerae O139 Bengal strains possess virulence factors common

Received 13 March 2000; revised version received 2 Aug. 2000; accepted 23 Aug. 2000.

Corresponding author: Dr G.B. Nair (e-mail: gbnair@vsnl. com).

§Present address: John Hopkins University, 624 N. Broadway, Baltimore, MD 21205, USA. to $\mathrm{O} 1 \mathrm{El}$ Tor and cause diarrhoea which is clinically indistinguishable from serotype $\mathrm{O} 1$ cholera $[7,8]$. Molecular epidemiological analyses such as zymovar analysis, ribotyping and pulsed-field gel electrophoresis (PFGE) showed that $V$. cholerae O139 Bengal resembles the seventh pandemic O1 El Tor biotype [9, 10]. In contrast to serotype $\mathrm{O} 1, V$. cholerae, O139 Bengal strains possess a short truncated form of LPS and are characterised by the presence of a capsular polysaccharide material [11].

To establish infection in the gut, vibrios express a number of co-ordinately regulated virulence factors, the most important of which are cholera toxin (CT), toxin co-regulated pilus (TCP) and the global regulatory element ToxR. Genes for CT $(\operatorname{ctx} A B)$ have been shown to be located on a 4.5-kb DNA segment called 'core region', flanked by one or more copies of a direct repeat sequence (RS) of $2.4-2.7 \mathrm{~kb}$ [12]. Recently, it has been demonstrated that a region of c. $7 \mathrm{~kb}$, comprising the core region and $\mathrm{RS} 2$, is not an integral part of the $V$. cholerae genome but is acquired by the site-specific lysogenic conversion by a filamentous bacteriophage CTX $\phi$ [13]. The genes for the expression of TCP, the important pilus colonisation factor, 
have been shown to be present along with other putative virulence genes on a 39.5-kb DNA segment collectively known as $V$. cholerae pathogenicity island (VPI) [14]. Recent studies have also shown that $V$. cholerae acquired VPI by lysogenic conversion by another filamentous phage $\operatorname{VPI} \phi[15]$.

$V$. cholerae, non-O1, non-O139 represent heterogeneous serogroups, which so far have not been recognised as having epidemic potential and are generally devoid of most of the virulence genes associated with the epidemic-causing serogroups (O1 and O139) of $V$. cholerae. However, the association of non-O1, nonO139 V. cholerae with sporadic cases of diarrhoea has been reported [16]. By biochemical tests, $V$. cholerae strains belonging to $\mathrm{O} 1$ and $\mathrm{O} 139$ serogroups are indistinguishable from their non-O1, non-O139 counterparts except for their ability to be agglutinated by specific antisera and their sensitivity to specific lytic phages $[3,16]$. Smooth variants of a given species in the genus Vibrio are characterised by the presence of both smooth ( $\mathrm{S}$; $\mathrm{O}$ antigens) and rough $(\mathrm{R})$ antigens, while rough variants express only the $R$ antigens. The exact genetic basis for the generation of a rough variant from a corresponding smooth variant or vice versa is not clearly understood at present. Serological studies have shown that $V$. cholerae strains possess identical $\mathrm{R}$ antigens irrespective of their $\mathrm{O}$ antigenic types [17] which need to be absorbed in the preparation of $\mathrm{O}$ specific antiserum. Organisms expressing only the $\mathrm{R}$ antigen are usually indistinguishable from the corresponding S-form by colony morphology and biochemical tests, but may be differentiated by agglutination with rough antiserum [3].

Many studies have focused on the biochemical constituents of $\mathrm{R}$ antigens of $V$. cholerae [18-21]. However, very limited information is available on the characterisation of the virulence genes of the rough variants of $V$. cholerae, particularly those isolated from clinical cases. Existing data on rough mutants of wildtype smooth virulent strains of $V$. cholerae show that these mutants are comparatively less virulent when tested in animal models [22], which has been attributed to their severe defect in small bowel colonisation properties when tested in the infant mouse model $[23,24]$. This study describes the extensive molecular characterisation of seven rough variants of $V$. cholerae isolated as the sole infecting pathogen from choleralike cases.

\section{Materials and methods}

\section{Bacterial strains}

Seven rough isolates of $V$. cholerae from the stools of hospitalised patients with cholera-like disease were included in this study. They were isolated as the sole pathogen from patients from different parts of India, as shown in Table 1. These isolates were indistinguishable from smooth variants of $V$. cholerae by biochemical tests, but agglutinated only with specific rough antiserum. Reference $V$. cholerae $\mathrm{O} 1$ classical biotype strain O395. El Tor biotype strains VC20 and MO1 and the O139 strain SG24 were included for comparison. All the isolates and reference strains were maintained in nutrient agar (NA) as stabs at room temperature.

\section{Analysis of bacterial LPS}

LPS profiles of the rough isolates and the reference strains of $V$. cholerae were analysed by SDS-PAGE of proteinase K-treated whole-cell lysates [25]. After electrophoresis, polysaccharide materials were fixed in the gel by treatment with ethanol-acetic acid fixative and silver stained [26] to visualise the LPS profiles.

\section{Detection of virulence genes by PCR}

Purified genomic DNA (c. $50 \mathrm{ng}$ ) were used as the template for PCR experiments with 0.75 units of Taq DNA polymerase (Takara, Kyoto, Japan) in a final reaction volume of $25 \mu \mathrm{l}$. In all PCR assays except for multiplex PCR with $c t x A$ - and $w b$-specific primers, each primer and each of four dNTPs were used at concentrations of $1 \mu \mathrm{M}$ and $200 \mu \mathrm{M}$, respectively, and 30 amplification cycles were performed. Nucleotide sequences of all primers and conditions for PCR are presented in Table 2 [27-32]. Multiplex PCR experiments for the detection of $c t x A$ - and $w b$-specific genes of either O1 or O139 origin were performed with specific primers to these genes as described previously [27]. The presence of $c t x A$ and tcp $A$ in $V$. cholerae strains was also detected by multiplex PCR assay with primers specific to these genes. In separate sets of PCR experiments, specific primer pairs were used for the detection of $\operatorname{ctx} B$, the regulatory gene tox $R$ and genes comprising the $V$. cholerae pathogenicity island (VPI) including $\operatorname{tag} A$, int, aldA, toxT, $L J$ and $R J$. Amplicons obtained with each set of PCR experiments were resolved with agarose gels, UV irradiated and documented with the Gel-Doc 2000 system (BioRad Laboratories, Hercules, CA, USA).

\section{CT assay}

The ability of $V$. cholerae strains to produce CT and the amount produced were determined by the $\mathrm{GM}_{1}$-ELISA assay with cultures grown in LB $(\mathrm{pH} 6.5)$ or AK1 $\left(\mathrm{pH} \mathrm{7.4)}\right.$ broth at $30^{\circ} \mathrm{C}$ for $16 \mathrm{~h}[33,34]$. Cell-free culture supernates were added to wells of a microtitration plate (Nunc, Kamstrup, Roskilde, Denmark) coated with $\mathrm{GM}_{1}$ (monosialoganglioside) (Sigma). Plates were sequentially treated with appropriately diluted (1 in 100) rabbit anti-CT serum, anti-rabbit Ig peroxidase conjugate (Sigma) and developed with the substrate solution containing O-phenelynediamine dihydrochloride $1 \mathrm{mg} / \mathrm{ml}$ and $\mathrm{H}_{2} \mathrm{O}_{2} \quad 0.12 \%$. For each set of experiments, known amounts of purified CT (Sigma) were used to generate a standard curve from which the 
Table 1. Characteristics of clinical isolates of $V$. cholerae used in this study

\begin{tabular}{|c|c|c|c|c|c|c|c|c|c|c|c|c|c|c|}
\hline \multirow[b]{3}{*}{ Isolates } & \multirow{3}{*}{$\begin{array}{l}\text { Place/date of } \\
\text { isolation }\end{array}$} & \multirow[b]{3}{*}{ Serogroup } & \multicolumn{12}{|c|}{ Detection of virulence genes* } \\
\hline & & & \multicolumn{2}{|c|}{$w b$ of } & \multicolumn{2}{|c|}{$\operatorname{ctx} \phi$} & \multicolumn{6}{|c|}{ VPI } & \multicolumn{2}{|c|}{ Regulatory elemen } \\
\hline & & & O1 & O139 & $c t x A$ & $c t x B$ & $\operatorname{tag} A$ & int & ald $A$ & tсp $A^{\dagger}$ & $L J$ & $R J$ & toxT & toxR \\
\hline ALO45 & $\begin{array}{l}\text { Allepy } \\
06.08 .96\end{array}$ & Rough & + & - & + & + & + & + & + & + & + & + & + & + \\
\hline ALO46 & $\begin{array}{l}\text { Allepy } \\
06.08 .96\end{array}$ & Rough & + & - & + & + & + & + & + & + & + & + & + & + \\
\hline MO77 & $\begin{array}{l}\text { Madras } \\
05.11 .92\end{array}$ & Rough & - & + & + & + & + & + & + & + & + & + & + & + \\
\hline MO99 & $\begin{array}{l}\text { Madras } \\
05.11 .92\end{array}$ & Rough & + & - & + & + & + & + & + & + & + & + & + & + \\
\hline DO66 & $\begin{array}{l}\text { Delhi } \\
19.03 .97\end{array}$ & Rough & + & - & + & + & + & + & + & + & + & + & + & + \\
\hline DO70 & $\begin{array}{l}\text { Delhi } \\
\text { 19.03.97 }\end{array}$ & Rough & + & - & + & + & + & + & + & + & + & + & + & + \\
\hline SG15 & $\begin{array}{l}\text { Calcutta } \\
20.11 .92\end{array}$ & Rough & + & - & + & + & - & + & + & + & + & - & + & + \\
\hline MO1 & $\begin{array}{l}\text { Madras } \\
05.11 .92\end{array}$ & $\mathrm{O} 1$ & + & - & + & + & + & + & + & + & + & + & + & + \\
\hline SG24 & $\begin{array}{l}\text { Calcutta } \\
14.12 .92\end{array}$ & O139 & - & + & + & + & + & + & + & + & + & + & + & + \\
\hline $\mathrm{VC} 20^{*}$ & $\begin{array}{l}\text { Calcutta } \\
07.05 .92\end{array}$ & $\mathrm{O} 1$ & + & - & + & + & + & + & + & + & + & + & + & + \\
\hline
\end{tabular}

+ , amplicon of similar size to that of the control; - , no amplicon.

Tested by PCR analysis with specific primers.

All these strains produced tcpA amplicons similar to that of $\mathrm{O} 1 \mathrm{El}$ Tor strain

El Tor biotype. 
Table 2 Nucleotide sequence of primers and the PCR conditions used in this study

\begin{tabular}{|c|c|c|c|c|c|c|}
\hline \multirow[b]{2}{*}{ Gene } & \multirow[b]{2}{*}{ Primer } & \multirow[b]{2}{*}{ Primer sequence $\left(5^{\prime}-3^{\prime}\right)$} & \multicolumn{3}{|c|}{ PCR conditions } & \multirow[b]{2}{*}{ Ref. no. } \\
\hline & & & Denaturing & Annealing & Extension & \\
\hline \multirow[t]{2}{*}{$w b \mathrm{O} 1$} & O1F2-1 & GTTTCACTGAACAGATGGG & $94^{\circ} \mathrm{C}, 60 \mathrm{~s}$ & $55^{\circ} \mathrm{C}, 60 \mathrm{~s}$ & $72^{\circ} \mathrm{C}, 60 \mathrm{~s}$ & 27 \\
\hline & O1R2-2 & GGTCATCTGTAAGTACAAC & & & & \\
\hline \multirow[t]{2}{*}{$w b 0139$} & O139F2 & AGCCTCTTTATTACGGGTGG & $94^{\circ} \mathrm{C}, 60 \mathrm{~s}$ & $55^{\circ} \mathrm{C}, 60 \mathrm{~s}$ & $72^{\circ} \mathrm{C}, 60 \mathrm{~s}$ & 27 \\
\hline & O139R2 & GTCAAACCCGATCGTAAAGG & & & & \\
\hline \multirow[t]{2}{*}{$\operatorname{ctx} B$} & $\operatorname{ctx} B-\mathrm{F}$ & GGTTGCTTCTCATCATCGAACCAC & $94^{\circ} \mathrm{C}, 60 \mathrm{~s}$ & $55^{\circ} \mathrm{C}, 90 \mathrm{~s}$ & $72^{\circ} \mathrm{C}, 90 \mathrm{~s}$ & 28 \\
\hline & $c t x B-\mathrm{R}$ & GATACACATAATAGAATTAAGGAT & & & & \\
\hline \multirow[t]{2}{*}{$\operatorname{ctx} A$} & $\operatorname{ctx} A 1$ & CTCAGACGGGATTTGTTAGGCACG & $94^{\circ} \mathrm{C}, 90 \mathrm{~s}$ & $60^{\circ} \mathrm{C}, 90 \mathrm{~s}$ & $72^{\circ} \mathrm{C}, 90 \mathrm{~s}$ & 29 \\
\hline & $\operatorname{ctx} A 2$ & TCTATCTCTGTAGCCCCTATTA CG & & & & \\
\hline \multirow{4}{*}{$\begin{array}{l}t c p A \\
\text { classical } \\
\text { tcp } A \text { El Tor }\end{array}$} & tcp $A-\mathrm{F}$ & CACGATAAGAAAACCGGTCAA GAG & $94^{\circ} \mathrm{C}, 90 \mathrm{~s}$ & $60^{\circ} \mathrm{C}, 90 \mathrm{~s}$ & $72^{\circ} \mathrm{C}, 90 \mathrm{~s}$ & 29 \\
\hline & tcp $A-\mathrm{R}$ & ACCAAATGCAACGCCGAATGGAGC & & & & \\
\hline & tcp $A-\mathrm{F}$ & GAAGAAGTTTGTAAAAGAAGA ACAC & $94^{\circ} \mathrm{C}, 90 \mathrm{~s}$ & $60^{\circ} \mathrm{C}, 90 \mathrm{~s}$ & $72^{\circ} \mathrm{C}, 90 \mathrm{~s}$ & 29 \\
\hline & tcpA-R & GAAAGGACCTTCTTTCACGTTG & & & & \\
\hline \multirow[t]{2}{*}{ toxR } & toxR $-\mathrm{F}$ & CGGGATCCATGTTCGGATTAGGACAC & $94^{\circ} \mathrm{C}, 30 \mathrm{~s}$ & $64^{\circ} \mathrm{C}, 30 \mathrm{~s}$ & $72^{\circ} \mathrm{C}, 30 \mathrm{~s}$ & 30 \\
\hline & toxR-R & CGGGATCCTACTCACACACTTTGATGGC & & & & \\
\hline \multirow[t]{2}{*}{ toxT } & toxt-F & ACTGTCGACGCAAAGCATATTCAGAGA & $94^{\circ} \mathrm{C}, 40 \mathrm{~s}$ & $55^{\circ} \mathrm{C}, 40 \mathrm{~s}$ & $72^{\circ} \mathrm{C}, 90 \mathrm{~s}$ & 31 \\
\hline & toxt $-\mathrm{R}$ & CGCGGATCCATACAATCGAAAATAGGA & & & & \\
\hline \multirow[t]{2}{*}{$\operatorname{tag} A$} & $\operatorname{tag} A-\mathrm{F}$ & GGTGGTAAGATATTCACTCTTAATG & $94^{\circ} \mathrm{C}, 40 \mathrm{~s}$ & $55^{\circ} \mathrm{C}, 40 \mathrm{~s}$ & $72^{\circ} \mathrm{C}, 40 \mathrm{~s}$ & 14 \\
\hline & $\operatorname{tag} A-\mathrm{R}$ & GAGACATCTATAGAATACTGG CTG & & & & \\
\hline \multirow[t]{2}{*}{ int } & int-F & GAAGTAATGAAACCGATAAGTGG & $94^{\circ} \mathrm{C}, 40 \mathrm{~s}$ & $55^{\circ} \mathrm{C}, 40 \mathrm{~s}$ & $72^{\circ} \mathrm{C}, 40 \mathrm{~s}$ & 32 \\
\hline & int- $\mathrm{R}$ & TGCTTTGTACCAGTCACAGATAG & & & & \\
\hline \multirow[t]{2}{*}{ ald $A$} & ald $A-\mathrm{F}$ & GCATCTGATTATGACCAAAGAATAGG & $94^{\circ} \mathrm{C}, 40 \mathrm{~s}$ & $55^{\circ} \mathrm{C}, 40 \mathrm{~s}$ & $72^{\circ} \mathrm{C}, 90 \mathrm{~s}$ & This study \\
\hline & ald $A-\mathrm{R}$ & GTCAATGGATGAAGCCACACAGTG- & & & & \\
\hline \multirow[t]{2}{*}{$L J$} & $L J-\mathrm{F}$ & GTGAATCTTGATGAGACGCTC TG & $94^{\circ} \mathrm{C}, 40 \mathrm{~s}$ & $55^{\circ} \mathrm{C}, 40 \mathrm{~s}$ & $72^{\circ} \mathrm{C}, 60 \mathrm{~s}$ & This study \\
\hline & $L J-\mathrm{R}$ & GGTGAGCCAGGCTTATTTGGG & & & & \\
\hline \multirow[t]{2}{*}{$R J$} & $R J-\mathrm{F}$ & TCGTTAGCGTGTCGGTTCGCAGG & $94^{\circ} \mathrm{C}, 40 \mathrm{~s}$ & $55^{\circ} \mathrm{C}, 40 \mathrm{~s}$ & $72^{\circ} \mathrm{C}, 90 \mathrm{~s}$ & This study \\
\hline & $R J-\mathrm{R}$ & TGCTTTGTACCAGTCACAGATAG & & & & \\
\hline
\end{tabular}

amount of CT in the test samples was interpolated. Results were expressed as $\mu \mathrm{g}$ of $\mathrm{CT}$ produced $/ \mathrm{ml}$ of supernate/opacity unit (at $540 \mathrm{~nm}$ ) of the bacterial cell suspension.

\section{Southern hybridisation analysis of rrn genes (ribotyping)}

Genomic DNA from $V$. cholerae strains was prepared by the cetyltrimethylammonium bromide-phenol extraction method [35] from $3 \mathrm{ml}$ of overnight cultures grown in LB broth at $37^{\circ} \mathrm{C}$. Purified DNA thus obtained was subjected to enzymic digestion with the restriction endonuclease $B g l \mathrm{I}$ and electrophoresed on an agarose $0.8 \%(\mathrm{w} / \mathrm{v})$ gel. Electrophoresed DNA fragments were transferred to a nylon membrane (Hybond- $\mathrm{N}^{+}$; Amersham Life Science, Little Chalfont, Bucks) and allowed to hybridised with the DNA probe specific for $r r n$ genes. The probe for $r r n$ genes consisted of a $7.5-\mathrm{kb}$ Bam HI fragment of the recombinant plasmid pKK3535 containing the r-RNA operon of Escherichia coli [36]. The probe was labelled with a chemiluminescent dye (ECL Labelling Kit, Amersham) and the probe-treated membrane was developed according to the manufacturer's protocol (ECL Detection Kit, Amersham).

\section{Computer-assisted analysis of patterns}

Quantity One software, version 4 (BioRad) was used to compare the hybridisation patterns obtained by $B g l \mathrm{I}$ ribotyping of $V$. cholerae strains. The software clustered strains with similar ribotypes. Defined-similarity dendrograms were generated and used to join the clusters by the neighbour-joining method. The pattern for each strain was checked by visual observation.

\section{Results}

\section{LPS profiles of rough variants of $V$. cholerae}

LPS profiles of the rough variants of $V$. cholerae along with strains belonging to $\mathrm{O} 1$ and $\mathrm{O} 139$ serogroups are presented in Fig. 1. The LPS profiles of rough variants (Fig. 1, lanes 1-7) were remarkably similar to each other, but differed considerably from those of the smooth variants belonging to either the $\mathrm{O} 1$ and $\mathrm{O} 139$ serogroups. LPS profiles of rough variants were found to be devoid of repetitive units of polysaccharides and were characterised by the presence of core oligosaccharides alone (indicated in Fig. 1). On the other hand, V. cholerae $\mathrm{O} 1$ strains belonging to $\mathrm{El}$ Tor biotype (Fig. 1 , lanes 8 and 9) were characterised by the presence of long repetitive units of polysaccharides along with core oligosaccharides migrating to the same region as seen for the rough variants. The LPS profile of O139 strain SG24 appeared to be somewhat truncated in nature, having short repetitive units of polysaccharides with core oligosaccharides (Fig. 1, lane 10).

\section{Presence of virulence genes in rough variants of V. cholerae}

Purified genomic DNA isolated from rough variants of $V$. cholerae strains were analysed by PCR for the presence of virulence genes found in toxigenic $V$. cholerae. Results with specific pairs of primers for the virulence genes of $V$. cholerae are summarised in Table 


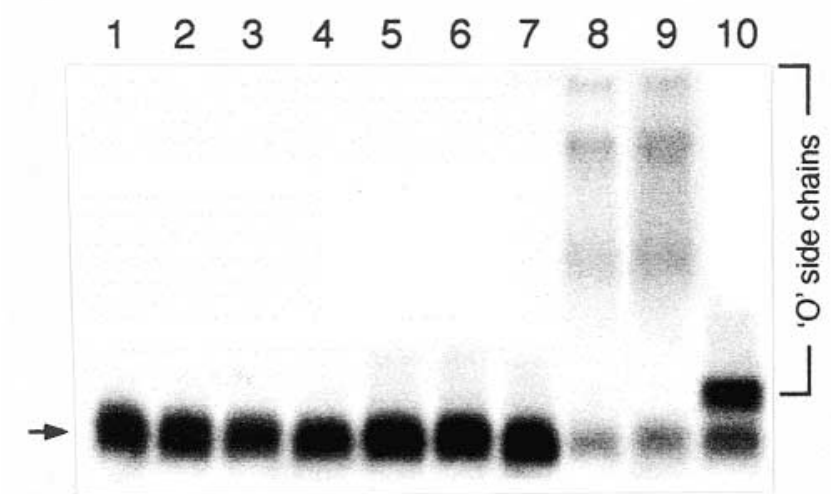

Fig. 1. LPS profiles of proteinase K-treated whole cells of rough variants (lanes 1-7), O1 (lanes 8, 9) and O139 (lane 10) V. cholerae isolates: lane 1, ALO45; 2, ALO46; 3, MO77; 4, MO99; 5, DO66; 6, DO70; 7, SG15; 8, MO1; 9, VC20; 10, SG24. Position of core oligosaccharide is indicated by arrow.

1. Interestingly, six of the seven rough variants of $V$. cholerae (ALO45, ALO46, MO99, DO66, DO70 and SG15) produced an $\mathrm{O} 1 w b$ gene-specific amplicon size of $192 \mathrm{bp}$ (Fig. 2, lanes 1,2,4-7) similar to that obtained with reference $\mathrm{O} 1 \mathrm{El}$ Tor strains $\mathrm{MO} 1$ and VC20 (Fig. 2, lanes 8 and 9). Strain MO77, on the other hand, produced a 449-bp O139 wb-specific amplicon (Fig. 2, lane 3) similar to that obtained with reference O139 strain SG24 (Fig. 2, lane 10). Each of these strains produced a 301-bp ctxA amplicon. Multiplex PCR with $\operatorname{ctx} A$ and $t c p A$ primers revealed that all seven rough variants were positive for these genes and the $t c p A$ amplicons of these strains were of El Tor type (Table 1). Amplicon sizes of 350, 344, 1115, 1101, 1010, 1499, 460 and $900 \mathrm{bp}$ were produced by all the rough variants of $V$. cholerae except SG15, when tested with the respective primers specific for $\operatorname{tag} A$, int, ald $A$, toxT, $L J, R J, c t x B$ and toxR. Strain SG15 was found to possess all these genes, but failed to produce an amplicon with primers specific to either $\operatorname{tag} A$ or $R J$ (Table 1), indicating that this strain has an altered VPI.

\section{Production of $C T$ by the rough variants of $V$. cholerae}

CT production by the rough variants of $V$. cholerae was studied by growing the strains in either LB, or AKI broth at $30^{\circ} \mathrm{C}$ for $16 \mathrm{~h}$ and measuring the amount of CT produced in the culture supernates by a $\mathrm{GM}_{1}$-ELISA. The summarised results are presented in Table 3. The rough variants of $V$. cholerae produced $\mathrm{CT}$ in liquid culture in amounts that varied from isolate to isolate. Five of seven rough variants (ALO45, ALO46, MO77, MO99 and SG15) produced more CT in AKI medium than in LB medium. On the other hand, two strains (DO66 and DO70) produced more toxin in LB medium than AKI medium (Table 3). As expected, LB culture conditions favoured $\mathrm{CT}$ production by the $\mathrm{O} 1$ classical strain (O395) and CT production by El Tor (VC20 and MO1) and $\mathrm{O} 139$ (SG24) strains was favoured in AKI culture conditions.

\section{Organisation of rrn genes in rough variants of $V$. cholerae}

The organisation of $r r n$ genes (ribotype) in the chromosome of the $V$. cholerae isolates was analysed by Southern hybridisation experiments with BglIdigested chromosomal DNA and the rRNA-specific DNA probe. Results generated in Southern blot experiments with the rough variants of $V$. cholerae are presented in Fig. 3. Reference $V$. cholerae O1 El Tor strains VC20 and MO1, and O139 strain SG24 showed ribotypes previously designated as RI, RII [37]

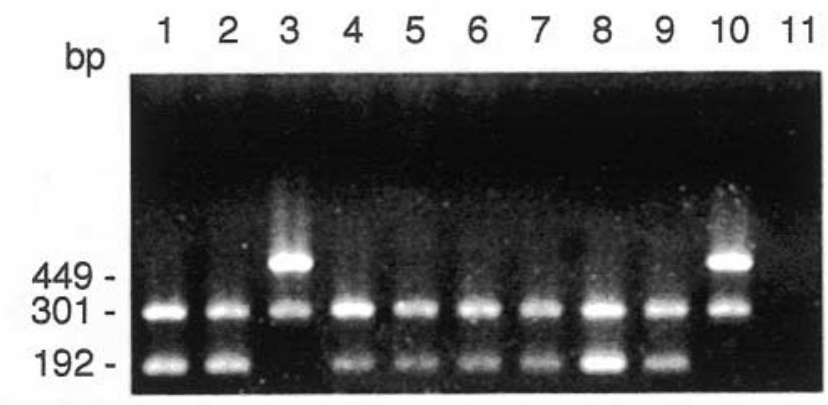

Fig. 2. Agarose gel electrophoresis of PCR amplicons obtained with primers specific for $c t x A$ and $w b$ of $\mathrm{O} 1$ and $\mathrm{O} 139$ V. cholerae isolates: lane 1, ALO45; 2, ALO46; 3, MO77; 4, MO99; 5, DO66; 6, DO70; 7, SG15; 8, MO1; 9, VC20; 10, SG24; 11, E. coli strain DH5 $\alpha$ as a negative control. Amplicon sizes of ctxA (301 bp), O1 wb (192 bp) and O139 $w b(449 \mathrm{bp})$ are indicated. 
Table 3. CT production by the rough isolates and reference strains of $V$. cholerae grown in different media

\begin{tabular}{llcc}
\hline \multirow{2}{*}{$\begin{array}{l}\text { Strain or } \\
\text { isolate no. }\end{array}$} & & \multicolumn{2}{c}{ Amount of $\mathrm{CT}^{*}$ produced in } \\
\cline { 3 - 4 } & Serogroup & $\mathrm{AKI}^{\dagger}$ & $\mathrm{LB}^{\ddagger}$ \\
\hline ALO45 & Rough & 0.15 & 0.02 \\
ALO46 & Rough & 0.14 & 0.02 \\
MO77 & Rough & 0.2 & 0.04 \\
MO99 & Rough & 0.24 & 0.03 \\
DO66 & Rough & 0.15 & 0.56 \\
DO70 & Rough & 5.80 & 8.6 \\
SG15 & Rough & 0.21 & 0.02 \\
MO1 & O1 & 0.03 & 0.01 \\
VC20 & O1 & 0.08 & 0.06 \\
O395" & O1 & 0.04 & 0.6 \\
SG24 & O139 & 0.04 & 0.01 \\
E. coli DH5 $\alpha$ & - & $<0.001$ & $<0.001$ \\
\hline
\end{tabular}

${ }^{*}$ Measured by $\mathrm{GM}_{1}$-ELISA and expressed as $\mu \mathrm{g}$ of CT produced $/ \mathrm{ml}$ of supernate/unit opacity $(540 \mathrm{~nm})$ of bacterial suspension. ${ }^{\dagger}$ Grown in AKI medium ( $\mathrm{pH}$ 7.4) [34] at $30^{\circ} \mathrm{C}$ for $16 \mathrm{~h}$.

${ }^{*}$ Grown in LB medium $(\mathrm{pH} 6.5)$ at $30^{\circ} \mathrm{C}$ for $16 \mathrm{~h}$.

${ }^{\S}$ El Tor biotype.

$\|$ Classical biotype.

and BI [38], respectively, and were included in Fig. 3 for comparison. The DNA probe specific to $r r n$ genes hybridised with eight-to-ten bands ranging in size from 15.0 to $2.1 \mathrm{~kb}$ in each $V$. cholerae isolate and the patterns could be classified into six different ribotypes. It is evident from Fig. 3 that rough variant $V$. cholerae strain SG15 (Fig. 3, lane 7) produced ribotype identical to that of reference O1 strain VC20 (Fig. 3, lane 9; RI)
Isolates ALO45 (Fig. 3, lane 1), ALO46 (Fig. 3, lane 2), DO66 (Fig. 3, lane 5) and DO70 (Fig. 3, lane 6) produced ribotypes identical to each other and belonged to the RIII ribotype of O1 El Tor strains which emerged after the 1992-1993 O139 epidemics [37]. On the other hand, isolate MO77 produced a ribotype pattern (Fig. 3, lane 3) (BII) [38] similar to the BI pattern obtained with reference O139 strain SG24 (Fig. 3, lane 10). Interestingly, the ribotype of isolate MO99 (Fig. 3, lane 4) appeared to be unique in nature as compared with the other $V$. cholerae isolates tested in this study.

\section{Discussion}

This study was initiated to understand the molecular characteristics of seven rough variants of $V$. cholerae isolated from hospitalised cases of cholera-like diarrhoea. Serogrouping of $V$. cholerae has been shown to be very useful in differentiating between epidemic and non-epidemic strains, with currently recognised epidemic strains belonging to either the O1 or O139 serogroups. However, the use and scope of serogrouping only applicable to the smooth variants of pathogenic bacteria including $V$. cholerae and has no, or very little, applicability to the rough variants. While much attention has been directed to study of the smooth variants of $V$. cholerae, very limited information is available regarding the virulence genes and their

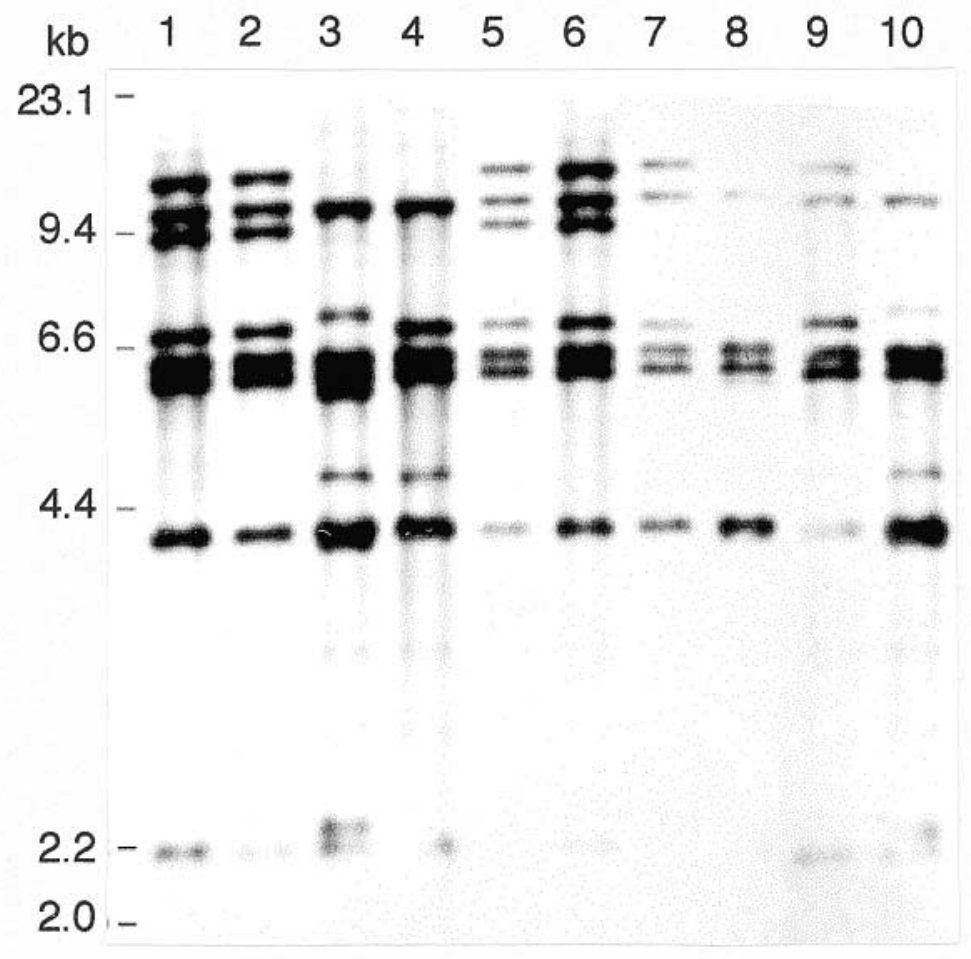

Fig. 3. Southern hybridisation analysis of BglI-digested genomic DNA from V. cholerae strains with a 7.5-kb Bam HI fragment of the E. coli rRNA clone pKK3535. V. cholerae strains: lane 1, ALO45; 2, ALO46; 3, MO77; 4, MO99; 5, DO66; 6, DO70; 7, SG15; 8, MO1; 9, VC20; 10, SG24. Positions of $\lambda$ HindIII molecular size markers are indicated. 
expression in rough variants of $V$. cholerae, particularly those isolated as the sole pathogen from clinical cases.

LPS profiles of rough variants of $V$. cholerae (Fig. 1) as documented in this study, clearly established that these strains are devoid of any repetitive units of polysaccharides and the LPS profiles of rough variants are identical despite being different ' $O$ ' lineages, as shown from the $w b$ analysis. Although the long repetitive units of polysaccharide form the basis of $\mathrm{O}$ antigenic specificity [2], an earlier study [39] demonstrated that with only the LPS core in the LPS profile, a non-O1, non-O139 strain (V315-1) was untypable but not rough [30]. Thus, the presence of only the core region in the LPS profile should not be construed as an exclusive phenotype of the rough characteristic. Interestingly, all these rough variants were found to be PCR positive with either $\mathrm{O} 1$ or $\mathrm{O} 139 w b$ (Table 1) whereas environmental isolates of rough variants were shown to be negative in both $\mathrm{O} 1$ and $\mathrm{O} 139 w b$ PCR (unpublished data). Earlier studies conducted in an animal mode with $w b$ mutants demonstrated the role of LPS in the pathogenesis of cholera [23, 24]. Despite the loss of the functional expression of the $\mathrm{O}$ antigenic marker of epidemic $V$. cholerae, these strains appeared to retain gene(s) responsible for the expression of epidemic-related $\mathrm{O}$ antigen. Detection of either $\mathrm{O} 1$ or O139 $w b$-specific genes in these clinical isolates as compared with the environmental rough variants has immense significance from the epidemiological point of view.

All seven rough variants of $V$. cholerae were found to possess $c t x A$ and $c t x B$ and expressed $C T$ in culture supernates (Table 3 ). The presence of tox $R$ in these strains was also established by PCR (Table 1). tox $R$ in these strains appeared to be functional, as evidence by the media-dependent regulation of CT expression observed in these isolates. However, the amount of $\mathrm{CT}$ produced by these isolates varied from strain to strain. While classical strain O395 produced more CT in LB, El Tor, O139 and five of the rough variants produced more CT in AKI medium. Interestingly, two rough strains DO66 and DO70, isolated from Delhi, India, produced more CT in LB than in AKI. All these strains produced less $\mathrm{CT}$ in nutrient broth than in either LB or AKI medium (data not shown). Interestingly, the amount of CT produced by the rough variants was much greater than that by O1 El Tor and O139 strains.

Epidemic isolates of $V$. cholerae $\mathrm{O} 1$ and $\mathrm{O} 139$ have been shown to possess the cluster of genes which comprise the VPI. As expected, clinical isolates of the rough variants studied here also possessed all the genes of the VPI with one exception, as evidenced by PCR with specific primers (Table 1). One of the seven rough strains (SG15) was found to be negative by PCR for $\operatorname{tag} A$ and $R J$, whereas the others were positive for all the genes sought in this study. Results obtained in multiplex PCR with $t c p A$ primers established that these rough variants are related to either O1 El Tor or O139 strains. These data are consistent with the findings that regulation of $\mathrm{CT}$ expression by these isolates, except for two Delhi isolates, was similar to that of El Tor or O139 strains.

$B g l$ I-generated ribotypes obtained in this study also indicate that these isolates possess at least nine copies of the rrn operon in their genomes. However, this needs further investigation to establish clearly the exact copy number of the rrn operon. rrn-mediated recombination may be one of the mechanisms by which pathogenic bacteria can maintain their genomic plasticity or diversity, and the possibility of genome rearrangements is greater when there are more rrn operons in an organism [40]. In this context, the significant finding from the ribotyping analysis was that these rough variants could be grouped with smooth variants of $V$. cholerae (Fig. 4) and these results are in agreement with that of the $w b$ PCR analysis. Dendrogram analysis, generated from ribotype patterns, clustered $\mathrm{O} 1 \mathrm{El}$ Tor strain $\mathrm{VC} 20$ with one rough variant SG15 which was isolated before the onset of the O139 epidemics in 1992. Strains isolated after the

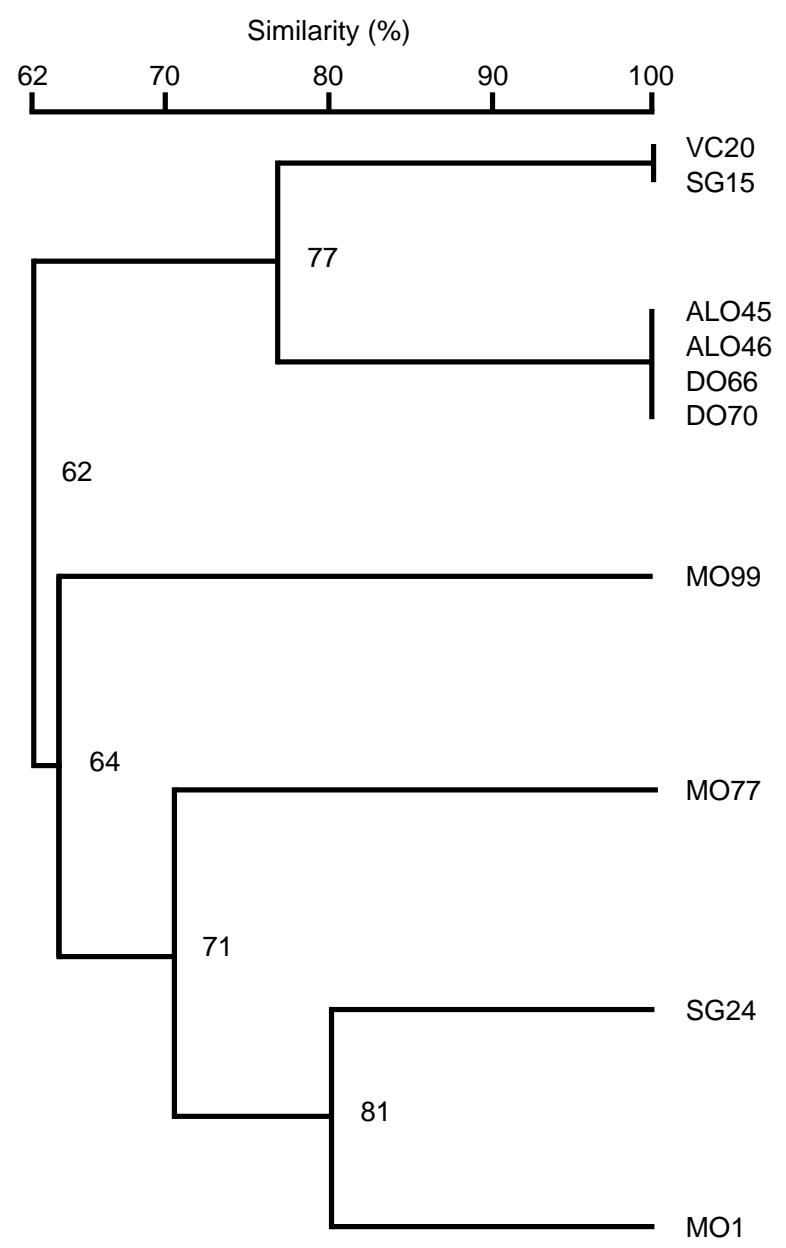

Fig. 4. Dendrogram generated by the average percentage of matched bands summarising the degree of similarity of BglI-ribotypes of $V$. cholerae isolates. 
onset of O139 epidemics, e.g., ALO45, ALO46, DO66 and DO77, clustered in another group closely related to O1 strain VC20 and had ribotype pattern (RIII) identical to those of the post-O139 El Tor O1 isolates [37]. These results are consistent with earlier findings which indicated that pre- and post-O139 O1 El Tor strains can be grouped on the basis of ribotype patterns[37]. As expected, dendrogram analysis placed SG24 and MO77 in the same lineage (Fig. 4). Furthermore, both the strains were positive with O139 $w b$-specific PCR (Fig. 2) and had similar but not identical ribotypes. The significance of these findings is yet to be elucidated. Perhaps horizontal transfer of genes including genes for $\mathrm{O}$ antigen biosynthesis may be facilitated in a strain with a 'rough' background. Interestingly, ribotypes of MO1 and MO99 which were O1 $w b$ PCR-positive, appeared to be more closely related to the $\mathrm{O} 139$ strains and were grouped with the $\mathrm{O} 139$ cluster. This is consistent with an earlier report which described MO1 as the progenitor strain of $V$. cholerae O139 [41]. Whether or not these rough variants are derived from the prevailing epidemic strains or act as a potential source for generation of newer variants with increased virulence, or both, is an area which needs to be addressed.

The significance of the occurrence of the rough strains of $V$. cholerae is still not properly understood. Epidemiological and surveillance studies have shown that the appearance of the rough strains of $V$. cholerae normally precedes the period when a shift of serotype from either Inaba to Ogawa or vice versa is observed. One of the rough strains (SG15) included in this study was isolated just before the first isolation of $V$. cholerae O139 in Calcutta in Nov. 1992. It is tempting to speculate that reversion to a rough variant is a state that makes the organism more amenable to change, perhaps by becoming more permeable to intake of foreign DNA than its smooth counterpart.

This research work was supported in part by grants from Japan International Corporation Agency (JICA/NICED Project no. 0541061-E-O) to NICED. R.K.N. is the recipient of an ad hoc Research Associateship from the Department of Biotechnology, Government of India. R.K.M. and R.K.N. contributed equally to the work presented here.

\section{References}

1. Yamai S, Okitsu T, Shimada T, Katsube Y. [Distribution of serogroups of Vibrio cholerae non-O1 and non-O139 with specific reference to their ability to produce cholera toxin, and addition of novel serogroups.] Kansenshogaku Zasshi 1997; 71: 1037-1045.

2. Manning PA, Stroeher UH, Morona R. Molecular basis for Oantigen biosynthesis in Vibrio cholerae O1: Ogawa-Inaba switching. In: Wachsmuth IK, Blake PA, Olsvik O (eds) Vibrio cholerae and cholera: molecular to global perspectives. Washington, DC, American Society for Microbiology. 1994: 77-94.

3. Sakazaki R. Bacteriology of Vibrio and related organisms. In: Barua D, Greenough WB (eds) Cholera. New York, Plenum Medical Book Company. 1992: 37-55.
4. Barua D. History of cholera. In: Barua D, Greenough WB (eds) Cholera. New York, Plenum Medical Book Company. 1992: 1-36.

5. Blake PA. Historical perspectives on pandemic cholera. In: Wachsmuth IK, Blake PA, Olsvik O (eds) Vibrio cholerae and cholera: molecular to global perspectives. Washington, DC, American Society for Microbiology. 1994: 293-295.

6. Shimada T, Nair GB, Deb BC, Albert MJ, Sack RB, Takeda Y. Outbreak of Vibrio cholerae non-O1 in Indian and Bangladesh. Lancet 1993; 341: 1347.

7. Bhattacharya SK, Bhattacharya MK, Nair GB et al. Clinical profile of acute diarrhoea cases infected with the new epidemic strain of Vibrio cholerae O139: designation of the disease as cholera. J Infect 1993; 27: 11-15.

8. Cholera Working Group, International Centre for Diarrhreal Diseases Research, Bangladesh. Large epidemic of cholera-like disease in Bangladesh caused by Vibrio cholerae 0139 synonym Bengal. Lancet 1993; 342: 387-390.

9. Berche P, Poyart C, Abachin E et al. The novel epidemic strain $\mathrm{O} 139$ is closely related to pandemic strain O1 Vibrio cholerae. J Infect Dis 1994; 170: 701-704.

10. Popovic T, Fields PI, Olsvik O et al. Molecular subtyping of toxigenic Vibrio cholerae O139 causing epidemic cholera in India and Bangladesh, 1992-1993. J Infect Dis 1995; 171: $122-127$.

11. Johnson JA, Salles CA, Panigrahi $\mathrm{P}$ et al. Vibrio cholerae O139 synonym Bengal is closely related to Vibrio cholerae El Tor but has important differences. Infect Immun 1994; 62: 2108-2110.

12. Pearson GDN, Woods A, Chiang SL, Mekalanos JJ. CTX genetic element encodes a site-specific recombination system and an intestinal colonization factor. Proc Natl Acad Sci USA 1993; 90: 3750-3754.

13. Waldor MK, Makalanos JJ. Lysogenic conversion by a filamentous phage encoding cholera toxin. Science 1996; 272: 1910-1914.

14. Karaolis DKR, Johnson JA, Bailey CC, Boedeker EC, Kaper JB, Reeves PR. A Vibrio cholerae pathogenicity island associated with epidemic and pandemic strains. Proc Natl Acad Sci USA 1998; 95: 3134-3139.

15. Karaolis DKR, Somara S, Maneval DR, Johnson JA, Kaper JB. A bacteriophage encoding a pathogenecity island, a type-IV pilus and a phage receptor in cholera bacteria. Nature 1999; 399: 375-379.

16. Morris JG. Non-O group 1 Vibrio cholerae strains not associated with epidemic disease. In: Wachsmuth IK, Blake PA, Olsvik O (eds) Vibrio cholerae and cholera: molecular to global perspectives. Washington, DC, American Society for Microbiology. 1994: 103-115.

17. Shimada T, Sakazaki R. R antigen of Vibrio cholerae. Jpn J Med Sci Biol 1973; 36: 155-160.

18. Kaca W, Brade L, Rietschel ET, Brade H. The effect of removal of D-fructose on the antigenicity of the lipopolysaccharide from a rough mutant of Vibrio cholerae Ogawa. Carbohydr Res 1986; 149: 293-298.

19. Kondo S, Haishima Y, Hisatsune K. Analysis of the 2-keto-3deoxyoctonate (KDO) region of lipopolysaccharides isolated from non-O1 Vibrio cholerae O5R. FEMS Microbiol Lett 1990; 68: $155-158$

20. Kondo S, Haishima Y, Hisatsune K. Location of fructose in lipopolysaccharide isolated from O1 Vibrio cholerae NIH 41R. FEMS Microbiol Lett 1993; 106: 93-98.

21. Vinogradov EV, Bock K, Holst O, Brade H. The structure of the lipid A-core region of the lipolysaccharides from Vibrio cholerae $\mathrm{O} 1$ smooth strain 569B (Inaba) and rough mutant strain 95R (Ogawa). Eur J Biochem 1995; 233: 152-158.

22. Baselski VS, Upchurch S, Parker CD. Isolation and phenotypic characterization of virulence-deficient mutants of Vibrio cholerae. Infect Immun 1978; 22: 181-188.

23. Angelichio MJ, Spector J, Waldor MK, Camilli A. Vibrio cholerae intestinal population dynamics in the suckling mouse model of infection Infect Immun 1999; 67: 3733-3739.

24. Baselski VS, Parker CD. Intestinal distribution of Vibrio cholerae in orally infected infant mice: kinetics of recovery of radiolabel and viable cells. Infect Immun 1978; 21: $518-525$.

25. Hitchcock PJ, Brown TM. Morphological heterogeneity among Salmonella lipopolysaccharide chemotypes in silver-stained polyacrylamide gels. J Bacteriol 1983; 154: 269-277. 
26. Tsai C-M, Frasch CE. A sensitive silver stain for detecting lipopolysaccharides in polyacrylamide gels. Anal Biochem 1982; 119: 115-119.

27. Hoschino K, Yamasaki S, Mukhopadhyay AK et al. Development and evaluation of a multiplex PCR assay for rapid detection of toxigenic Vibrio cholerae O1 and O139. FEMS Immunol Med Microbiol 1998; 20: 201-207.

28. Olsvik O, Wahlberg J, Petterson B et al. Use of automated sequencing of polymerase chain reaction-generated amplicons to identify three types of cholera toxing subunit B in Vibrio cholerae O1 strains. J Clin Microbiol 1993; 31: 22-25.

29. Keasler SP, Hall RH. Detection and biotyping of Vibrio cholerae $\mathrm{O} 1$ with multiplex polymerase chain reaction. Lancet 1993; 341: 1661.

30. Ghosh C, Nandy RK, Dasgupta SK, Nair GB, Hall RH, Ghose AC. A search for cholera toxing (CT), toxin coregulated pilus (TCP), the regulatory element ToxR and other virulence factors in non-O1/ non-O139 Vibrio cholerae. Microb Pathog 1997; 22: $199-208$.

31. Carroll PA, Tashima KT, Rogers, MB, DiRita VJ, Calderwood SB. Phase variation in tcpH modulates expression of the ToxR regulon in Vibrio cholerae. Mol Microbiol 1997; 25: 1099-1111.

32. Kovach ME, Shaffer MD, Peterson KM. A putative integrase gene defines the distal end of a large cluster of ToxR-regulated colonization genes in Vibrio cholerae. Microbiology 1996; 142: 2165-2174.

33. Holmgren J. Comparison of the tissure receptors for Vibrio cholerae and Escherichia coli enterotoxins by means of gangliosides and natural cholera toxoid. Infect Immun 1973; 8: $851-859$.

34. Iwanaga M, Yamamoto $\mathrm{K}$, Higa N, Ichinose $\mathrm{Y}$, Nakasone N, Tanabe M. Culture conditions for stimulating cholera toxin production by Vibrio cholerae O1 EI Tor. Microbiol Immunol 1986; 30: 1075-1083.

35. Murray MG, Thompson WF. Rapid isolation of high molecular weight plant DNA. Nucleic Acids Res 1980; 8: 4321-4325.

36. Brosius J, Ullrich A, Raker MA et al. Construction and fine mapping of recombinant plasmids containing the $r r n B$ ribosomal RNA operon of E. coli. Plasmid 1981; 6: 112-118.

37. Sharma C, Nair GB, Mukhopadhyay AK, Bhattacharya SK, Ghosh RK, Ghosh A. Molecular characterization of Vibrio cholerae O1 biotype EI Tor strains isolated between 1992 and 1995 in Calcutta, India: evidence for the emergence of a new clone of the EI Tor biotype. J Infect Dis 1997; 175: 1134-1141.

38. Faruque SM, Saha MN, Asadulghani, et al. Genomic diversity among Vibrio cholerae O139 strains isolated in Bangladesh and India between 1992 and 1998. FEMS Microbiol Lett 2000; 184: $279-284$.

39. Nandy RK, Sengupta TK, Mukhopadhyay S, Ghose AC. A comparative study of the properties of Vibrio cholerae O139, O1 and other non-O1 strains. J Med Microbiol 1995; 42: 251-257.

40. Krawiec S, Riley M. Organization of the bacterial chromosome. Microbiol Rev 1990; 54: 502-539.

41. Pajni S, Sharma C, Bhasin N et al. Studies on the genesis of Vibrio cholerae O139: identification of probable progenitor strains. J Med Microbiol 1995; 42: 20-25. 